\title{
A PERSPECTIVA DE CONSTRUÇÃO DO ALEITAMENTO MATERNO COMO DIREITO HUMANO FUNDAMENTAL
}

Bruna Tereza Pereira ${ }^{1}$

\begin{abstract}
Resumo: A presente pesquisa tem como objeto de estudo o aleitamento materno, sendo exigência parcial para obtenção do título de Mestre em Serviço Social, junto ao Programa de Pós-Graduação Stricto Sensu em Serviço Social, pela Universidade Estadual do Oeste do Paraná, campus de Toledo-Pr, com área de concentração em "Serviço Social, Políticas Sociais e Direitos Humanos". Objetivou-se compreender o objeto de pesquisa como um direito humano fundamental, partindo do entendimento de que a prática da amamentação contribui para a promoção e defesa dos direitos humanos fundamentais, em especial o Direito Humano à Alimentação Adequada e o Direito à Saúde, ao ampliar o acesso ao primeiro alimento do ser humano: o leite materno. Para atingir tal objetivo, a pesquisa fundamentou-se em referenciais teóricos a partir da perspectiva de alguns autores que discutem a temática.
\end{abstract}

Palavras-chave: aleitamento materno; direito à alimentação; direito à saúde.

\section{THE PERSPECTIVE OF CONSTRUCTION OF BREASTFEEDING AS A FUNDAMENTAL HUMAN RIGHT}

\begin{abstract}
The present study aims at the study of breastfeeding, being partial requirement to obtain the Master's degree in Social Work, together with the Stricto Sensu Post-Graduation Program in Social Work, by the State University of the West of Paraná, Toledo- Pr, with area of concentration in "Social Work, Social Policies and Human Rights". The objective was to understand the research object as a fundamental human right, starting from the understanding that the practice of breastfeeding contributes to the promotion and defense of fundamental human rights, especially the Human Right to Adequate Food and the Right to Health, by expanding the access to the first food of the human being: the mother's milk. To reach this objective, the research was based on theoretical references from the perspective of some authors who discuss the theme.
\end{abstract}

Keywords: breastfeeding; right to food; right to health.

\section{Introdução}

A infância é um período no qual se desenvolvem grande parte das potencialidades humanas e, desta maneira, o aleitamento materno é um modo insubstituível de fornecer o alimento ideal para o crescimento e desenvolvimento saudável das crianças. Por isso, a Organização Mundial da Saúde e o Ministério da Saúde recomendam o aleitamento materno exclusivo por seis meses e complementado, quando a criança recebe além do leite materno, qualquer alimento sólido ou semissólido com a finalidade de complementá-lo e não substituí-lo até dois anos ou mais, pois não há vantagens de ingerir os alimentos complementares antes dos seis meses, já que o leite materno é capaz de suprir todas as necessidades nutricionais da criança, sendo a mais importante fonte de nutrientes, especialmente de proteínas, gorduras e vitaminas.

O interesse pelo objeto em estudo - o aleitamento materno - nasceu a partir da experiência de Estágio Supervisionado em Serviço Social I e II na graduação, sendo realizado na Associação Beneficente de Saúde do Oeste do Paraná - HOESP, em 2014 e 2015, proporcionando maior aproximação com a temática. A HOESP possui serviços especializados de atenção materna e/ou infantil, entre eles: Banco de Leite Humano (BLH), que fica em anexo à

\footnotetext{
${ }^{1}$ Assistente Social e Mestre em Serviço Social pelo Programas de Pós-Graduação em Serviço Social, com área de concentração em "Serviço Social, Políticas Sociais e Direitos Humanos" pela Unioeste, campus de Toledo-PR.
} 
HOESP, no município de Toledo/PR, na qual faz parte da $20^{\circ}$ Regional de Saúde e é credenciada aos atendimentos pelo Sistema Único de Saúde - SUS, sendo responsável por ações de promoção, proteção e apoio ao aleitamento materno exclusivo.

Este também é um espaço vinculado ao exercício profissional da Assistente Social da instituição através do desenvolvimento de projetos voltados para as mães em defesa e incentivo à prática da amamentação exclusiva, com informações socioeducativas, efetivação das leis que defendem está prática dentro da instituição, bem como através do desenvolvimento de campanhas e ações em incentivo a doação de leite materno.

Assim, com a inserção como aluna regular no Programa de Pós-Graduação stricto sensu em Serviço Social, nível mestrado, da Universidade Estadual do Oeste do Paraná, campus de Toledo-Pr, com área de concentração em "Serviço Social, Políticas Sociais e Direitos Humanos", no ano de 2017, deu-se continuidade aos estudos do objeto de pesquisa, a partir dos resultados obtidos na pesquisa de campo do Trabalho de Conclusão de Curso defendido em 2016 para obtenção do título de bacharel em Serviço Social, pela Universidade Estadual do Oeste do Paraná - UNIOESTE, campus de Toledo/PR, que objetivo identificar e analisar as causas que levaram à prática do desmame precoce por parte das mulheres atendidas na Associação Beneficente de Saúde do Oeste do Paraná - HOESP, no ano de 2015.

Através da pesquisa evidenciou-se que o desmame precoce é uma realidade presente na sociedade, efetivado com a introdução de outros alimentos e/ou líquidos durante o período de amamentação exclusiva, correspondendo a $100 \%$ da amostra, composta por doze (12) mulheres. E somente quatro (04) das entrevistadas continuaram amamentando o bebê após a introdução de uma alimentação complementar conforme as recomendações do Ministério da Saúde, em que devesse amamentar até as crianças completarem dois anos ou mais (PEREIRA, 2016).

Deste modo, a introdução de uma alimentação complementar no período da amamentação exclusiva foi o segundo principal motivo elencado pelas entrevistadas que levou a prática do desmame precoce. Embora apareça como segunda causa este é um dos principais motivos identificados pelo Ministério da Saúde que leva a efetivação do desmame precoce, contudo esta relação é pouco perceptível ou ignorada pela sociedade em geral, justamente pela naturalização e mitos que envolvem esta prática - como é o caso, por exemplo, do chamado "leite fraco", "falta de leite" ou "o bebê não quer pegar o peito".

Mesmo que tenham sido elencados diferentes motivos que levaram as mulheres a desmamar precocemente, em todos houve a introdução precoce de alimentos e líquidos. Mais além, nos casos de dificuldades na prática da amamentação os médicos foram os primeiros a recomendar uma alimentação artificial, através dos leites industrializados, podendo relacionar 
este fato aos valores interiorizados na sociedade brasileira de que o leite materno precisa ser complementado em qualquer situação, antes mesmo de serem diagnosticadas as situações de dificuldades e superação das mesmas.

Desta maneira, através do estudo para obtenção do título de Mestre em Serviço Social, estabeleceu-se como objetivo geral identificar se o discurso produzido pela promoção comercial do leite industrializado interfere na prática do aleitamento materno e em sua consolidação enquanto um direito humano. Para isso, tornou-se necessário compreender o objeto de pesquisa como um direito humano fundamental, partindo da compreensão que a prática da amamentação contribui para a promoção e defesa dos direitos humanos fundamentais, em especial o Direito Humano à Alimentação Adequada e o Direito à Saúde, ao ampliar o acesso ao primeiro alimento do ser humano: o leite materno.

Importa ressaltar que o profissional Assistente Social, quando inserido nos espaços sócio ocupacionais vinculados à política de saúde, também faz parte desta equipe de saúde, sendo este tema um campo fecundo de apropriação para a profissão, já que a defesa do aleitamento materno, em especial a amamentação exclusiva, perpassa pela defesa dos direitos humanos e sociais. Assim, percebe-se que este é um tema inovador para o Serviço Social, pois não há muitas publicações sobre este tema, ficando restrito apenas as produções e discussões aos profissionais da área de saúde, como enfermeiros e médicos e algumas publicações por parte de outros profissionais, como os nutricionistas.

Além disso, o profissional Assistente Social dispõe de ângulos particulares de observação e interpretação da realidade social e das demandas, por isso é importante que este atue na democratização das informações referente ao objeto em estudo, afim de facilitar o acesso das demandas aos serviços de saúde e na defesa intransigente dos direitos humanos fundamentais e sociais, entre eles: à saúde, à alimentação saudável e, sobretudo, o direito à vida.

A abordagem do assistente social sobre o aleitamento materno não deve ser de cunho biológico, médico-clínico, mas sob um olhar mais profundo para os fatores que norteiam a prática da amamentação, com uma leitura da realidade social e do contexto familiar em que esta mulher está inserida, já que os aspectos sociais, culturais, econômicos e ideológicos influenciam na efetivação do desmame precoce.

Desta maneira, a importância de o profissional assistente social apropriar-se deste tema perpassa justamente por estes elementos, pois a falta de informação dos profissionais de saúde e a falta de conhecimento da população são fatores centrais que influenciam na interrupção da amamentação exclusiva. A compreensão e qualificação acerca da temática do aleitamento materno exclusivo por parte dos profissionais de saúde, incluindo o assistente social, e o acesso 
às informações que lhe permitam compreender o ato de amamentar, desmistificando mitos, crenças, preconceitos, superando os medos e inseguranças e identificando as possíveis dificuldades e intercorrências neste período são requisitos para o enfrentamento do desmame precoce e para garantia do Direito Humano à Alimentação Adequada e o Direito à Saúde das crianças desde os primeiros dias de vida.

A partir disso, objetivou-se propiciar o entendimento de que o direito à saúde perpassa pelo direito à alimentação saudável e nutrição infantil desde os primeiros dias de vida da criança e que estes são requisitos básicos para a promoção e proteção da saúde. Sendo assim, a adoção de políticas de apoio ao aleitamento materno e à amamentação exclusiva configura-se como estratégia complementar das políticas de saúde pública, com resultados positivos sobre a mulher e principalmente à criança.

\section{Amamentar, Por Quê?}

Compreende-se que o aleitamento materno não é somente um ato biológico, natural, mas sim uma prática influenciada por determinantes sociais, econômicos, políticos, culturais e ideológicos que ao longo dos anos induziu e produziu diferentes discursos perante à prática da amamentação, tornando-a uma prática regulável pela sociedade e imbricada por dúvidas, medos, crenças e mitos que juntamente com os outros determinantes acabaram por consolidar à prática do desmame precoce e a responsabilizar a mulher por tal ato. Então, primeiramente, a pergunta a ser feita é: Por que amamentar?

O conhecimento científico adquirido nas últimas décadas sobre os benefícios da amamentação oferece as respostas que vão desde as propriedades biológicas do leite humano até as questões de cunho econômico, que são capazes de causar impacto tanto na família quanto no Estado, o que nos permite afirmar que não há outra forma de alimentar os bebês que seja equivalente ao aleitamento materno.

Deste modo, "as vantagens da amamentação sobre a alimentação artificial são enormes, sob qualquer ângulo que se examine: morbidade, mortalidade, segurança alimentar, economia, ecologia, bem-estar psíquico e social, qualidade de vida, praticidade e muitos outros" (BRASIL, 2009a, p. 16). Os benefícios à saúde das crianças são os mais difundidos, por terem sido amplamente divulgados a partir da década de 1980 nas campanhas oficiais de promoção da amamentação, influenciando os aspectos nutricionais, imunológicos, emocionais e fisiológicos das crianças, de acordo com Almeida (1999).

Nesse sentido, o leite materno contém todos os nutrientes essenciais capazes de suprir todas as necessidades nutricionais da criança e tem a capacidade natural de adequar-se as 
necessidades imunológicas e afetivas do bebê, pois contém mais de 200 substâncias (água, proteínas, células, sais minerais, carboidratos, gorduras, enzimas, hormônios, entre outros) que promovem o desenvolvimento adequado do sistema imunológico e a maturação do sistema digestivo e neurológico. Assim, de acordo com a Organização Mundial da Saúde (OMS) classifica-se como:

Aleitamento Materno Exclusivo: quando a criança recebe leite materno (direto da mama ou ordenhado), ou leite humano de outra fonte, sem outros líquidos ou sólidos (com exceção de gotas ou xaropes contendo vitaminas, sais de reidratação oral, suplementos minerais ou medicamentos); Aleitamento Materno: quando a criança recebe leite materno diretamente da mama ou ordenhado, ou leite humano de outra fonte, independentemente de receber ou não outros alimentos; Aleitamento Materno Misto ou Parcial: quando a criança recebe leite humano e outros tipos de leite; Aleitamento Materno Complementado: quando a criança recebe, além de leite humano, qualquer alimento sólido ou semissólido, com a finalidade de complementá-lo, e não de substituí-lo. Nessa categoria a criança pode receber, além do leite humano, outro tipo de leite, mas este não é considerado alimento complementar; Alimento Complementar: qualquer alimento, sólido ou semissólido, fabricado ou preparado localmente, próprio para uso como complemento do leite materno, quando esse torna-se insuficiente para satisfazer as necessidades nutricionais dos lactentes; Substituto do Leite Materno: qualquer alimento comercializado ou de outra forma apresentado como substituto parcial ou total do leite humano, seja ou não, adequado para este fim (BRASIL, 2017, p. 57).

Ainda, o desmame precoce se caracteriza pela introdução de qualquer tipo de alimento ou bebida, incluindo águas, chás ou sucos na alimentação da criança, diminuindo a ingesta do leite materno e interrompendo a amamentação exclusiva; e o processo de desmame, pela transição progressiva da alimentação com leite materno, para alimentação com a dieta da família, interrompendo completamente a amamentação, conforme Simons (2001).

Segundo o Ministério da Saúde "o desmame não é um evento, e sim um processo que faz parte da evolução da mulher como mãe e do desenvolvimento da criança. Nessa lógica, o desmame deveria ocorrer naturalmente, na medida em que a criança vai adquirindo competências para tal (BRASIL, 2009b, p. 63). Assim, no desmame natural a criança se auto desmama e raramente isso ocorre antes de um ano de idade.

O desmame natural proporciona uma transição mais tranquila, menos estressante para a mãe e a criança, preenche as necessidades da criança (fisiológicas, imunológicas e psicológicas) até ela estar madura para tal e, teoricamente, fortalece a relação mãe-filho. O desmame abrupto deve ser desencorajado, pois, se a criança não está pronta, ela pode se sentir rejeitada pela mãe, gerando insegurança e, muitas vezes, rebeldia. Na mãe, o desmame abrupto pode precipitar ingurgitamento mamário, estase do leite e mastite, além de tristeza ou depressão, e luto pela perda da amamentação ou por mudanças hormonais. É importante que a mãe não confunda o auto desmame natural com a chamada "greve de amamentação" do bebê. Esta ocorre principalmente em crianças menores de um ano, é de início súbito e inesperado, a criança parece 
insatisfeita e em geral é possível identificar uma causa: doença, dentição, diminuição do volume ou sabor do leite, estresse e excesso de mamadeira ou chupeta. Essa condição usualmente não dura mais que 2-4 dias. A mulher, com frequência, sente-se pressionada a desmamar, muitas vezes contra a sua vontade e sem ela e o bebê estarem prontos para tal. Existem vários mitos relacionados à amamentação dita "prolongada", tais como as crenças de que aleitamento materno além do primeiro ano é danoso para a criança sob o ponto de vista psicológico, que uma criança jamais desmama por si própria, que a amamentação prolongada é um sinal de problema sexual ou necessidade materna e não da criança, e que a criança que mama fica muito dependente. Algumas mães, de fato, desmamam para promover a independência da criança. No entanto, é importante lembrar que o desmame provavelmente não vai mudar a personalidade da criança. Além disso, o desmame forçado pode gerar insegurança nela, o que dificulta o processo de independização (BRASIL, 2009b, p. 64).

De acordo com Almeida (1999), é consenso na literatura, do ponto de vista nutricional, que o leite humano contém nutrientes em quantidade e qualidade necessários para propiciar o desenvolvimento adequado do lactente ${ }^{2}$, e "as vantagens imunológicas relativas à amamentação, que constam nos inúmeros trabalhos publicados na última década, podem ser sintetizadas em uma única frase: cada mamada é uma vacina” (ALMEIDA, 1999, p. 17), porém o autor destaca que as vantagens assumem uma dupla conotação quando comparadas diante das diferenças de classe social:

para a população de baixa renda, trata-se de um importante elemento de prevenção de doenças carenciais no primeiro ano de vida, a exemplo da desnutrição protéico-energética. Para as comunidades ricas, assume um caráter preventivo em relação à obesidade e demais intercorrências resultantes da superalimentação do lactente (ALMEIDA, 1999, p. 17).

Desta forma, vários são os benefícios da amamentação, principalmente a amamentação exclusiva. Há fortes evidências de que o leite materno protege as crianças contra a diarreia e essa proteção tende a diminuir quando o aleitamento materno deixa de ser exclusivo. Além de evitar a diarreia, a amamentação também exerce influência na gravidade dessa doença, já que crianças não amamentadas têm um risco três vezes maior de desidratarem e até mesmo morrerem por diarreia, quando comparadas com as crianças amamentadas, de acordo com Giugliani (2004).

A amamentação também diminui a gravidade de infecções respiratórias, sendo que o aleitamento materno previne a hospitalização de bebês por pneumonia no primeiro ano de vida, conforme estudos realizados em diversos países, inclusive no Brasil, e divulgados pelo Ministério da Saúde e a Organização Mundial da Saúde. Ainda, segundo o MS, amamentar exclusivamente nos primeiros seis meses de vida, evita ou diminui a chance de a criança desenvolver alergias, como alergia à proteína do leite de vaca, de dermatite atópica, asma, entre

\footnotetext{
2 "Lactente: criança com idade até 11 (onze) meses e 29 (vinte e nove) dias" (BRASIL, 2006a, s.p.).
} 
outros. A introdução precoce do leite de vaca além de desenvolver alergias e intolerâncias a este alimento também é um determinante para a diabete mellitus tipo I, podendo aumentar o risco do seu aparecimento em 50\%. Ao retardar a introdução de outros alimentos na dieta da criança temse a maturação do seu intestino, pois o leite materno favorece o amadurecimento da mucosa intestinal, prevenindo o aparecimento de alergias, principalmente em crianças com histórico familiar positivo para essas doenças (BRASIL, 2009b).

Recentemente, uma pesquisa desenvolvida no Departamento de Morfologia do Instituto de Ciências Biológicas da Universidade Federal de Minas Gerais e divulgada no ano de 2018 revelou ainda mais sobre a importância do aleitamento materno para o desenvolvimento dos indivíduos, pois de acordo com a pesquisa, o fígado pode ter uma formação diretamente prejudicada com a interrupção precoce da amamentação (HOJE EM DIA, 2018, s.p).

Além disso, quando a criança usa chupetas ou mamadeiras, o palato bucal é empurrado para cima, o que dificulta o alinhamento correto dos dentes e uma boa oclusão dentária, elevando a cavidade nasal e diminuindo o tamanho do espaço reservado para a passagem do ar pelo nariz, prejudicando a respiração nasal. Segundo Eny e Nascimento (2001), muitas mães não têm conhecimento acerca da importância da higienização de chupetas e mamadeiras, sendo que estas são as principais disseminadoras de infecções.

Também, há evidências que o aleitamento materno exclusivo diminui, em longo prazo, os riscos de hipertensão, colesterol alto e diabetes. Conforme pesquisas divulgadas pela OMS, os indivíduos amamentados apresentaram riscos bem inferiores de desenvolver algum tipo dessas doenças, e ainda, não é só o indivíduo amamentado que adquire proteção contra diabetes, mas também a mulher que amamenta, com uma redução de $15 \%$ na incidência de diabetes tipo II para cada ano de lactação.

O tema sobre a obesidade infantil vem sendo amplamente discutido, pois o Brasil atualmente é líder em obesidade infantil entre crianças de 9 a 11 anos, ultrapassando países como China e Estados Unidos, o que é preocupante. Sabe-se que muitos são os fatores que contribuem para esse quadro, como os índices de prevalência do aleitamento materno quando bebês, a publicidade de ultra processados voltada ao público infantil e a falta de alimentos saudáveis nas escolas.

Há estudos que avaliam a relação entre obesidade em crianças maiores de 03 anos de idade e o tipo de alimentação nos primeiros meses de vida, verificando-se que as crianças que haviam sido amamentadas apresentavam menor frequência de sobrepeso ou obesidade. Um dos possíveis fatores que fazem com que a amamentação reduza o risco de obesidade é que o leite materno contém um hormônio chamado leptina, o qual atua na inibição do apetite e no 
processamento dos nutrientes pelo organismo. Assim, a criança amamentada desde o nascimento será um adulto com mais facilidade de sentir-se saciada no futuro (BRASIL, 2009a). Ainda, outro estudo científico realizado por pediatras da Universidade de São Paulo (USP) mostrou que $80 \%$ das crianças com obesidade deixaram de ser amamentadas antes dos seis meses (CLIMEP, 2018, s.p.).

Do mesmo modo, também há efeitos positivos da amamentação para o desenvolvimento da cavidade bucal do bebê, pois o exercício de retirar o leite da mama é de extrema importância para o desenvolvimento adequado de sua cavidade oral, facilitando o alinhamento correto dos dentes e de uma boa oclusão dentária. Sendo assim, o desmame precoce também poderá levar à interrupção do desenvolvimento motor-oral adequado, podendo prejudicar as funções de mastigação, deglutição, respiração e articulação dos sons da fala (BRASIL, 2009b).

Bem como, de acordo com Giugliani (2004) há benefícios igualmente acerca do desenvolvimento cognitivo das crianças que foram amamentadas exclusivamente, desenvolvendo facilidades quando começam a ler e escrever, pois as substâncias do leite materno aperfeiçoam o desenvolvimento cerebral, sendo associado ao melhor desempenho em teste de inteligência, repercutindo em maiores níveis de escolaridade.

Além disso, pela composição completa do leite materno na qual protege as crianças de várias doenças, os índices de mortalidade entre crianças amamentadas são inferiores quando comparadas as crianças que não foram amamentadas. De acordo com o Ministério da Saúde estima-se que o aleitamento materno evita $13 \%$ das mortes em crianças menores de cinco anos em todo o mundo, não existindo nenhuma outra estratégia isolada que alcance tamanho impacto na redução da mortalidade infantil (BRASIL, 2009b. E desta maneira, milhões de vidas estão sendo salvas a cada ano por causa da amamentação exclusiva. Além disso, recentemente

estudos demonstraram que o leite materno possui algumas células pluripotentes, chamadas "stem cells" - como as células tronco - que são resistentes o suficiente para conseguir passar pela barreira ácida do estômago e entrar no intestino do bebê, onde são absorvidas. Atingem a corrente sanguínea e, a partir daí se alojam em determinados tecidos onde se diferenciarão nas células correspondentes. Isto significa que estas células podem produzir, nos bebês que mamam, mais células musculares, células intestinais, neurônios, células do sangue ou do fígado, por exemplo. O leite materno, portanto, oferece ao pequeno bebê que acabou de nascer um "plus" de células novas (ESCOBAR, 2018, s.p.).

Da mesma forma, há efeitos positivos para a mãe que amamenta. $\mathrm{O}$ ato de amamentar faz com que os seios voltem ao normal mais rápido, favorece a recuperação pós-parto, pois ao amamentar a mãe promove a aceleração da involução uterina reduzindo o sangramento no pósparto, além de proteger a mãe de anemias, diabetes e diminuir as chances de contrair doenças 
como câncer de mama e ovário. O risco de contrair câncer de mama diminui 4,3\% a cada 12 meses de amamentação. Já para o câncer de ovário, para cada mês de amamentação reduz em $2 \%$ o risco de contrair essa doença.

A amamentação também é um excelente método anticoncepcional nos primeiros seis meses após o parto, com 98\% de eficácia, desde que a mãe esteja amamentando exclusiva ou predominantemente e ainda não tenha menstruado, sendo que a ovulação após o parto está totalmente relacionada com a frequência da amamentação, pois mulheres que ovulam antes do sexto mês após o parto normalmente amamentam menos vezes por dia (BRASIL, 2009b).

Desta maneira, de acordo com Giugliani (2004), a amamentação também traz benefícios psicológicos para a criança e para a mãe, sendo uma estratégia natural de fortalecer os laços afetivos entre mãe e filho, oportunizando afeto, intimidade, confiança e diversos outros sentimentos. Assim, a amamentação é a primeira comunicação entre mãe e bebê: "para o binômio mãe-bebê, o AM configura-se como oportunidade de interação contribuindo para o estabelecimento de vínculos afetivos que resultam em maior segurança para mãe e promoção do desenvolvimento afetivo-emocional social da criança" (BRASIL, 2017, p.13).

Ademais, o aleitamento materno exclusivo oferece a vantagem de diminuir os custos das famílias e dos estabelecimentos de saúde. De acordo com Almeida (1999, p. 17) "a criança que mama no peito necessita apenas $5 \%$ de um salário mínimo para suprir todas as suas necessidades vitais". Assim, ao eliminar os gastos com leites artificiais, mamadeiras ou chupetas, melhora-se a qualidade de vida das famílias, já que as crianças amamentadas adoecem com menos frequência e necessitam de menos atendimento médico, medicamentos, hospitalização, prevenindo doenças futuras tanto para a mãe como para o bebê.

Em relação ao Estado, os aspectos relacionados à saúde e à economia têm merecido lugar de destaque nas publicações. A adoção de políticas de promoção e apoio à amamentação é apresentada como uma estratégia supletiva de saúde pública, cuja eficácia já foi comprovada em diferentes sociedades, com diferentes graus de complexidade e desenvolvimento. Os efeitos positivos advêm, inicialmente, da melhora individual do estado da criança e da mulher, e, posteriormente, do impacto sobre a coletividade, mediante o somatório dos ganhos individuais, resultando em benefícios plurais para a sociedade. Alguns autores reafirmam que o compromisso da criação de um estado-nação mais digno no futuro passa pela capacidade de construção de gerações saudáveis e com maior potencial intelectual, evocando, para tanto, a prática da amamentação exclusiva até o sexto mês (ALMEIDA, 1999, p. 17-18).

Contudo, apesar das evidências científicas que apontam que quase todas as mulheres podem amamentar, sabe-se que "algumas vezes, a amamentação pode ser temporária ou definitivamente interrompida porque a mãe encontra-se muito abalada física ou psiquicamente, como nas doenças cardíacas, renais e hepáticas graves, nos quadros de psicose e de depressão 
pós-parto grave" (BRASIL, 2009a, p. 49). Assim, entre as condições que restringem a amamentação, as mais frequentes estão relacionadas à mãe, como infecções maternas através de alguns vírus ou doenças, o uso de fármacos contraindicados para este período, o uso de drogas de abuso ou ilícitas, a ingestão sem moderação de álcool e o tabagismo. As condições relacionadas as crianças incluem algumas doenças metabólicas muito raras e o nascimento prematuro (BRASIL, 2009a).

Porém, tanto as doenças infecciosas maternas quanto o uso de fármacos não contraindicam a amamentação, no entanto, dentro de outras condições surgem as dúvidas se a amamentação pode ser fator de risco para a saúde das crianças e nessas situações tornam-se mais difíceis as tomadas de decisões, exigindo uma avaliação criteriosa dos riscos, benefícios e viabilidade de manter a amamentação. Assim, sabe-se que existem algumas condições em que se justifica incluir as fórmulas infantis e/ou ingredientes apropriados para a sua preparação entre as opções de alimentação da criança.

\begin{abstract}
Alimentação de substituição é entendida como o processo de alimentar uma criança que não está sendo amamentada com uma dieta capaz de proporcionar todos os nutrientes necessários até que ela seja completamente alimentada com os alimentos da família. A alimentação de substituição apropriada para os lactentes, de acordo com a Organização Mundial da Saúde (WORLD HEALTH ORGANIZATION, 2008), deve ser aquela escolhida pela família após ter recebido o aconselhamento de profissionais habilitados e que atenda aos seguintes requisitos: ser aceitável, factível, acessível, sustentável e segura (BRASIL, 2009a, p. 54).
\end{abstract}

No preâmbulo do Código Internacional de Comercialização de Substitutos do Leite Materno, a OMS reconhece que existe um mercado legítimo para as fórmulas infantis e para os ingredientes apropriados para a sua preparação quando as mães não amamentam ou o fazem apenas parcialmente e que todos esses produtos devem ser acessíveis por meio de sistemas de distribuição comerciais ou não comerciais a todos que deles necessitam e que não devem ser comercializados ou distribuídos de maneira a interferir na proteção e promoção do aleitamento materno, contudo, sabe-se que o que ocorre na maioria das vezes é que são prescritos outros líquidos, denominados como os substitutos do aleitamento materno aos bebês menores de 6 meses, sem uma justificativa com base científica para tal substituição. Deste modo,

o uso de uma alimentação de substituição deve sempre levar em conta três fundamentos: (1) a escolha da melhor opção no contexto da mãe; (2) a proteção das mães e crianças que podem praticar a amamentação; e (3) o cumprimento à Norma Brasileira de Comercialização de Alimentos para Lactentes e Crianças de Primeira Infância, Bicos, Chupetas e Mamadeiras (NBCAL) (BRASIL, 2009a, p. 54). 
Logo, deve-se sempre considerar o conhecimento de que o leite materno é o alimento ideal, a ponto de se recomendar sua exclusividade durante os seis primeiros meses de vida das crianças. Felizmente, no Brasil com a existência de uma rede nacional de Bancos de Leite Humano ampliam-se as possibilidades para lidar com as situações em que o aleitamento materno é contraindicado ou difícil de ser mantido.

Portanto, a resposta para a pergunta inicial está descrita acima através de todos os benefícios citados. Amamentar é importante porque a criança, a mulher, a família e o Estado, todos indistintamente, são amplamente beneficiados com a prática da amamentação exclusiva. Por isso, entendemos que o aleitamento materno como uma prática que contribui para a promoção e defesa do Direito Humano à Alimentação Adequada e o Direito à Saúde, pois nos referimos ao leite materno como o primeiro alimento que qualquer ser humano deveria ter acesso e, mais ainda, que ao longo dos primeiros seis meses de vida representa o único alimento necessário, seguro e nutricional, capaz de promover e proteger a saúde e suprir todas as demandas nutricionais da criança.

\section{Defesa do Direito Humano à Alimentação Adequada e à Saúde}

Atualmente através da consolidação dos estudos dos direitos humanos, tem-se produzido mudanças significativas no campo do direito internacional e, como consequência, no âmbito interno dos Estados: a valorização da pessoa humana e o respaldo jurídico internacional propiciou mudanças nas legislações, como aconteceu no Brasil, isto porque os direitos humanos são faculdades que o direito atribui às pessoas relativamente a vida, liberdade, igualdade, participação sociopolítica ou a qualquer outro aspecto fundamental que afete o correspondente desenvolvimento integral da pessoa, cabendo ao Estado proporcionar o máximo de bem-estar possível aos indivíduos e promover condições para que toda pessoa possa se desenvolver com dignidade na sociedade (GUERRA, 2008).

Ou seja, direitos humanos são todos os direitos relacionados à garantia de uma vida digna a todas as pessoas, são direitos e liberdades consideradas fundamentais para dignidade e são garantidos à pessoa pelo simples fato de ser humana, sem qualquer tipo de discriminação, como cor, religião, nacionalidade, gênero, orientação sexual e política, conforme Guerra (2008).

Assim, de acordo com Forti e Brites (2013) os direitos humanos, enquanto reflexão filosófica, tem suas raízes na história da Grécia clássica e em pensadores romanos dos séculos III ou II antes de Cristo. Posteriormente, na Idade Média, com a reintrodução na Europa das elaborações filosóficas da antiguidade, São Tomás de Aquino iniciou o esforço em conciliar a fé cristã com o direito natural predominantemente laico dos antigos. 
Contudo, durante esse período histórico tão longo, os direitos humanos configuraram-se tão somente como especulações que brotavam de cérebros isolados, sem correspondência na realidade social, pois tanto a antiguidade greco-romana escravista, quanto o feudalismo medieval europeu, eram modos de produção e de organização da sociedade fundados no status social da desigualdade e na inexistência de liberdade universal. Para o direito, o escravo, era uma mercadoria como outra qualquer, tendo por sina o trabalho forçado para o seu proprietário, sob a ameaça de castigos corporais. Já o servo medieval não passava de um pertence da gleba onde nascera, obrigado por toda a vida a prestar trabalhos gratuitos ao seu senhor, sem liberdade de ir e vir, e sem nada que se assemelhasse à noção moderna do sujeito de direito universal (FORTI; BRITES, 2013, p. 15, grifo do autor).

Desta maneira, identifica-se que esses modos de produção eram incompatíveis com o direito natural preexistente. Posteriormente, com o fortalecimento da burguesia, está tomou consciência - de acordo com seus interesses de classe - que os modos de produção se mantinham como obstáculos à livre acumulação e circulação de capital, à livre contratação de força de trabalho e à livre transformação em mercadoria de todos os produtos do trabalho e, assim, passou a "beber nas fontes filosóficas do direito natural, tomando-as como armas de combate para seu empenho de transformar a sociedade em função dos seus interesses" (FORTI; BRITES, 2013, p. 16). Sendo assim, mediante a uma série de processos revolucionários operados pela burguesia, o direito natural passou dos textos filosóficos para a existência social e política, tendo como marcos alguns documentos como: o Bill of Rights da Revolução Inglesa de 1688, as Declarações de Direitos da Revolução Americana, particularmente sua Declaração de Independência em 1776, e a Declaração dos Direitos do Homem e do Cidadão em 1789.

O Bill of Rights pôs fim ao regime de monarquia absoluta, no qual todo poder emana do rei e em seu nome é exercido, garantindo a liberdade pessoal, a propriedade privada, a segurança pessoal, o direito de petição, a proibição de penas cruéis, dentre outras, estabelecendo uma nova forma de organização do Estado cuja função precípua é a de proteção dos direitos da pessoa humana. Já a Declaração de Independência Norte-Americana inaugura uma nova etapa para a proteção do indivíduo, pois trate-se do primeiro documento a afirmar princípios democráticos na história política moderna, é o primeiro documento de natureza política que reconhece a soberania popular, a existência de direitos que se aplicam a todas pessoas sem que haja distinção de sexo, cor ou qualquer outra manifestação social. E, a Declaração dos Direitos do Homem e do Cidadão que representa o primeiro elemento constitucional do novo regime político (GUERRA, 2008).

A Declaração Francesa pode ser considerada a certidão de nascimento dos direitos humanos na modernidade ocidental, seja por seu simbolismo ou pela influência política mundial que exerceu. “(...) inspirada nos ideários de Liberdade, Igualdade e Fraternidade, serviu para desencadear um novo sentimento entre as pessoas que não haviam experimentado até então" (GUERRA, 2008, p. 11). 
A Revolução Francesa, desencadeou a supressão das desigualdades entre indivíduos e grupos sociais [...]. Na tríade famosa, foi sem dúvida a igualdade que representou o ponto central do movimento revolucionário. A liberdade, para os homens de 1789 , consistia justamente na supressão de todas as peias sociais ligadas à existência de estamentos ou corporações de ofícios. E a fraternidade, como virtude cívica, seria o resultado necessário a abolição de todos os privilégios (GUERRA, 2008, p. 11).

Esses documentos inauguraram no direito positivo, os chamados direitos civis e políticos, sendo considerados atributos inerentes a cada pessoa, e não como uma relação histórica, mutável e socialmente estabelecida. Essa concepção inicial dos direitos humanos considerava como direitos inerentes ao ser humano o direito à liberdade, à vida e à propriedade (FORTI; BRITES, 2013). "As declarações de direitos norte-americanas e a francesa representam a emancipação histórica do indivíduo perante os grupos sociais aos quais ele sempre se submeteu: a família, o estamento, o clã, as organizações religiosas etc" (GUERRA, 2008, p. 11-12).

Vemos, pois, que o direito internacional clássico não reconhecia a condição da pessoa como sujeito de direito, ao contrário, a visão era extremamente restritiva. "Somados aos pontos acima indicados, podemos identificar algumas ações significativas ainda no século XIX e seus desdobramentos no século XX, no processo de internacionalização dos direitos humanos, que se estende até os dias atuais" (GUERRA, 2008, p. 12), as três vertentes da proteção internacional da pessoa humana: direito humanitário, os direitos humanos e o direito dos refugiados.

O Comitê Internacional da Cruz Vermelha é o grande responsável pela difusão das normas de direito internacional humanitário, "se apresenta como uma organização imparcial, neutra e independente que tem como missão precípua proteger a vida das pessoas, bem como levar assistência a todos aqueles que são vítimas de guerra e de violência no âmbito interno dos Estado" (GUERRA, 2008, p. 22), objetivando "minimizar as dores e angústias produzidas em conflito armado, resguardando, assim, o núcleo que fundamenta todo o estudo dos direitos humanos: a dignidade da pessoa que mesmo em tempo de conflito armado deve ser respeitada" (GUERRA, 2008, p. 23).

Ainda, o processo de internacionalização dos direitos humanos também ganha impulso com a formação da Liga das Nações e a criação da Organização Internacional do Trabalho OIT. Com o fim da Primeira Guerra Mundial, concebeu-se o projeto de criação da Liga das Nações, que correspondia a uma organização intergovernamental de natureza permanente, baseada nos princípios da segurança coletiva e da igualdade entre os Estados.

Em 1919, “a Liga das Nações estabeleceu alguns pressupostos interessantes para a valorização dos direitos humanos no plano internacional [...] ao estabelecer que os Estados não devem recorrer à guerra e pautar as relações internacionais ancoradas na justiça e na honra, 
demonstra a finalidade de estabelecer proteção ao indivíduo (GUERRA, 2008, p. 31). Propõe também mecanismos para manutenção da paz e segurança coletiva.

Desde a Revolução Industrial havia um forte apelo para que fossem asseguradas e protegidas prerrogativas dos trabalhadores, haja vista as condições insalubres e precárias em que as atividades eram desenvolvidas. Deste modo, o surgimento da OIT é uma resposta aos anseios dos movimentos sindicais que pressionavam os Estados pela criação de uma organização que pudesse estabelecer mecanismos de proteção aos trabalhadores. Assim, também em 1919, surge a OIT "cuja finalidade é a de promover a universalização dos princípios da justiça social, especialmente daqueles consagrados por esse tratado como fundamentais ao Direito do Trabalho e à Previdência Social" (GUERRA, 2008, p. 33).

Posteriormente, com o advento da Segunda Guerra Mundial as atividades da OIT foram paralisadas. No pós-guerra, devido as violações e atrocidades praticadas durante este período em relação à dignidade humana, especialmente aos horrores praticados nos campos de concentração da Alemanha nazista, impõe-se a comunidade internacional o resgate da noção de direitos humanos, sendo o grande estopim para que pudessem ocorrer mudanças significativas. "Se a Segunda Guerra significou a ruptura com os direitos humanos, o Pós-Guerra deveria significar a sua reconstrução" (GUERRA, 2008, p. 42), passando a reconhecer que os indivíduos possuem direitos inerentes à sua existência e que devem ser protegidos.

Segundo Forti e Brites (2013), através da Carta de São Francisco em 1945 foi criada a Organização das Nações Unidas (ONU) e estabeleceu dentre suas metas desenvolver relações entre as nações baseadas no respeito ao princípio da igualdade de direitos e autodeterminação dos povos. A partir disso, iniciou-se as negociações políticas entre a União Soviética e os países capitalistas que resultou na Declaração Universal dos Direitos Humanos, em 10 de dezembro de 1948, declarando os direitos fundamentais para todas as pessoas independentes de sexo, cor, raça, idioma, religião, opinião, entre outros. A Declaração, ao tentar inaugurar uma conciliação entre os direitos estabelecidos na Declaração Francesa e os direitos postulados pelos trabalhadores, consolida a ideia de uma ética universal, combinando o valor de liberdade com o valor da igualdade, enumerando tanto direitos civis e políticos como direitos sociais, econômicos e culturais.

Ainda, de acordo com Guerra (2008), o estudo do Direito Internacional dos Direitos Humanos pode ser apresentado em quatro grandes momentos a partir da Carta da Organização das Nações Unidas: 1) a Declaração Universal de Direitos Humanos, de 1948; 2) a celebração dos Pactos de Direitos Civis e Políticos e o Pacto de Direitos Econômicos, Sociais e Culturais, em 1966; 3) as Convenções Internacionais universais de temas específicos, tais como: convenção 
sobre eliminação sobre todas as formas de discriminação contra a mulher, convenção sobre os direitos da criança, etc.; 4) de 1989 até os dias atuais. Deste modo,

Direitos Humanos são aqueles que os seres humanos possuem, única e exclusivamente, por terem nascido e serem parte da espécie humana. São direitos inalienáveis, o que significa que não podem ser tirados por outros, nem podem ser cedidos voluntariamente por ninguém e independem de legislação nacional, estadual ou municipal específica. Devem assegurar às pessoas condições básicas que lhes permitam levar uma vida digna. Isto é, com acesso à liberdade, à igualdade, ao trabalho, à terra, à saúde, à moradia, à educação, à água e alimentos de qualidade, entre outros requisitos essenciais (BRASIL, 2013a, p. 24 apud LEÃO; RECINE, 2011).

A partir disso, com os documentos acima citados, o Brasil também reconhece e incorpora a garantia dos direitos humanos no país. Na Declaração Universal dos Direitos Humanos a alimentação passa a ser um direito humano fundamental reconhecido, do mesmo modo também, a saúde, a maternidade e a infância.

A alimentação expressa as relações sociais, valores e história do indivíduo e dos grupos populacionais e tem implicações diretas na saúde e na qualidade de vida. A abordagem relacional da alimentação e nutrição contribui para o conjunto de práticas ofertadas pelo setor saúde, na valorização do ser humano, para além da condição biológica e o reconhecimento de sua centralidade no processo de produção de saúde (BRASIL, 2013a, p. 22).

Assim, entende-se que alimentação adequada é um direito fundamental do ser humano, inerente à dignidade da pessoa humana e indispensável à realização dos direitos consagrados na $\mathrm{CF}$, cabendo ao poder público adotar as políticas e ações que se façam necessárias para promover e garantir a segurança alimentar e nutricional da população (BRASIL, 2006b). Além disso, compreendemos a saúde através de determinantes e condicionantes, como: a alimentação, a moradia, o saneamento básico, o meio ambiente, o trabalho, a renda, a educação, a atividade física, o transporte, o lazer e o acesso aos bens e serviços essenciais (BRASIL, 1990), sendo um "direito de todos e dever do Estado, garantido mediante políticas sociais e econômicas que visem a redução do risco de doenças e de outros agravos e ao acesso universal e igualitário ás ações e serviços para sua promoção, proteção e recuperação" (BRASIL, 1988). Deste modo, “a alimentação e nutrição constituem-se requisitos básicos para a promoção e proteção da saúde, possibilitando a afirmação plena do potencial de crescimento e desenvolvimento humano, com qualidade de vida e cidadania" (BRASIL, 2013b, p. 10).

Mais além, percebe-se que a questão alimentar e nutricional está relacionada com diferentes interesses e diversos determinantes sociais, culturais, políticos, econômicos e ideológicos, por isso sua concepção ainda é assunto debatido por variados segmentos da sociedade, tanto no âmbito internacional quanto nacional. Diante disso, o conceito de Segurança 
Alimentar e Nutricional (SAN) está em permanente construção, evolui à medida que avança a história da humanidade e alteram-se a organização social e as relações de poder em uma sociedade, acompanhando as diferentes necessidades de cada povo e época. (BRASIL, 2013a).

Da mesma forma, assim também ocorre com o direito à saúde. Nosso objetivo aqui não é fazer uma retomada histórica, porém cabe ressaltar que este direito perpassa por todas as transformações sociais e políticas que permearam a construção do Estado brasileiro, de acordo com os diferentes interesses de quem estava no poder. Assim, marcado pela tensão entre interesses econômicos, a compreensão da saúde sofreu várias contradições na ordem social brasileira, porém a partir das lutas sociais da década de 1980.

Conforme Bravo (1996), o projeto de Reforma Sanitária foi fruto de lutas e mobilizações dos profissionais de saúde, articulados ao movimento popular. Tinha-se como preocupação central assegurar que o Estado atue em função da sociedade, pautando-se na concepção de Estado democrático e de direito, responsável pelas políticas sociais e, por conseguinte, pela saúde, através da defesa do Sistema Único de Saúde. Como fundamentos dessa concepção, destacam-se: melhor explicitação do interesse público, democratização do Estado e criação de uma esfera pública com controle social. Além disso, a proposta da Reforma Sanitária visava a: democratização do acesso, universalização das ações, descentralização, melhoria da qualidade dos serviços com adoção de um novo modelo assistencial pautado na integralidade e equidade das ações. Portanto, buscava-se garantir a saúde como direito de todos e dever do Estado.

Este movimento progrediu-se significativamente, culminando na criação do Sistema Único de Saúde (SUS) e no reconhecimento da saúde como direito fundamental, herança de paradigmas da Declaração Universal de Direitos Humanos.

Em 2006, o direito humano à alimentação adequada passou a ser assegurado por meio da Lei Orgânica N 11.346, criando o Sistema Nacional de Segurança Alimentar e Nutricional SISAN e definindo o seguinte conceito de SAN no Art. ${ }^{\circ}$ 3:

A Segurança Alimentar e Nutricional consiste na realização do direito de todos ao acesso regular e permanente a alimentos de qualidade, em quantidade suficiente, sem comprometer o acesso a outras necessidades essenciais, tendo como base práticas alimentares promotoras de saúde que respeitem a diversidade cultural e que sejam ambiental, cultural, econômica e socialmente sustentáveis (BRASIL, 2006b, s.p).

De acordo com os tratados internacionais de direitos humanos, existem duas dimensões indivisíveis do Direito Humano à Alimentação Adequada: o direito de estar livre da fome e da má nutrição; e o direito à alimentação adequada. Assim, a alimentação para o ser humano deve ser entendida como processo de transformação da natureza em gente saudável e cidadã, por isso esse direito diz respeito a todas as pessoas, de todas as sociedades e classe sociais, não apenas a 
aquelas que não tem acesso aos alimentos, e a promoção e plena realização deste direito envolve elementos de justiça social e econômica (BRASIL, 2013a).

Os problemas relacionados com a privação de alimentos devem ser abordados sob a perspectiva do Direito Humano à Alimentação Adequada. Isso significa que as estratégias de segurança alimentar e nutricional e as de redução da fome e da pobreza devem incorporar vários princípios de direitos humanos: Dignidade humana: Esse princípio exige que todas as pessoas sejam tratadas com respeito e dignidade. Políticas públicas baseadas em direitos humanos reconhecem o indivíduo não como mero objeto de uma política, mas sim como titular de direitos humanos, que pode reivindicá-los; Prestação de Contas (ou responsabilização): Uma abordagem baseada em direitos humanos reconhece a fixação de metas e processos transparentes para promover o desenvolvimento e a redução da pobreza. Os Estados são responsáveis por suas ações perante os indivíduos e delas devem prestar contas; Apoderamento: Os indivíduos, por sua vez, precisam apoderar-se das informações e instrumentos de direitos humanos para que possam reivindicar do Estado ações corretivas e compensações pelas violações de seus direitos (BRASIL, 2013a, p. 32).

Mais além, em 2010 a alimentação, juntamente com a saúde e a proteção à maternidade e à infância, foi incorporada à Constituição Federal como um direito social. Logo,

A inclusão da alimentação como direito social na Constituição Brasileira é fruto da ampla mobilização social e, portanto, uma reafirmação da sociedade brasileira de que a insegurança alimentar é uma inaceitável violação da dignidade humana e necessita de esforços coletivos para ser superada. É importante ressaltar que a "alimentação como um direito humano" reaquece tanto os debates relacionados com as situações de privação alimentar quanto os relacionados com as consequências da má qualidade da alimentação, tais como obesidade, diabetes, hipertensão, dislipidemias e alguns tipos de câncer, por exemplo, uma vez que tais situações também descrevem o estado de insegurança alimentar e a nutrição dos indivíduos (BRASIL, 2013a, p. 54).

Posto isso, a evolução do conceito de SAN aproxima-se cada vez mais da abordagem de Direitos Humanos à Alimentação Adequada e para que esse direito seja garantido deve-se incorporar princípios e ações essenciais para a garantia da promoção da realização dos mesmos. Sendo assim, as ações e estratégias nacionais e internacionais de promoção, proteção e apoio ao aleitamento materno

ao contribuir para a garantia da segurança alimentar e nutricional, com foco particular em crianças em situação de risco e vulnerabilidade social e individual, a exemplo de recém-nascidos de baixo peso e de muito baixo peso, induz a adesão à amamentação e o acesso ao leite humano de qualidade, sem comprometer outras necessidades das famílias (BRASIL, 2017, p. 28).

Ainda, "ao afirmar que determinado grupo ou indivíduo está em estado de segurança alimentar e nutricional, considera-se que este grupo ou indivíduo está tendo acesso regular a alimentação e nutrição adequada e está tendo plenas condições de aproveitar, em termos 
fisiológicos, os alimentos ingeridos" (BRASIL, 2013a, p. 33). Então, "o direito humano à alimentação adequada trata da disponibilidade, adequação, acesso físico, econômico e estável aos alimentos, respeitando a dignidade humana, garantindo prestação de contas e apoderamento dos titulares de direito" (BRASIL, 2013a, p. 33).

Nesse sentido, a partir dos compromissos definidos internacionalmente, como vimos, o Brasil ao promover, proteger e apoiar a prática do aleitamento materno, tem-se posicionado em defesa dos direitos humanos através da defesa do direito à alimentação, sobretudo uma alimentação segura e nutricional, e a defesa do direito à saúde, pois através das evidências cientificas sobre os benefícios do aleitamento materno, temos a convicção de que este é uma fonte para promoção e proteção da saúde e proporciona à adequada alimentação e nutrição infantil desde os primeiros dias de vida da criança.

Desta maneira, "para contemplar todos estes atributos são necessárias políticas articuladas entre diversos setores (políticas intersetoriais) e âmbitos da sociedade, que ofereçam condições concretas para que os diferentes grupos sociais, cada um com suas especificidades, acessem, com dignidade, alimentos de qualidade produzidos de modo sustentável e permanente" (BRASIL, 2013a, p. 33). Logo, compreendemos que a alimentação e a nutrição são requisitos básicos para a promoção e proteção da saúde e a adoção de políticas em apoio ao aleitamento materno configura-se como estratégia complementar das políticas de saúde pública, com resultados positivos sobre a mulher e a criança. Portanto, através das estratégias e ações que são a base para a consolidação da Política Nacional de Promoção, Proteção e Apoio ao Aleitamento Materno no Brasil temos um importante aparato jurídico em defesa dos direitos humanos, pois através dessa Política objetiva-se legitimar valores relacionados à dignidade humana. Também, “é por meio da política de $\mathrm{SAN}^{3}$, articulada a outros programas e políticas públicas correlatas, que o Estado deve respeitar, proteger, promover e prover o Direito Humano à Alimentação Adequada" (BRASIL, 2013a, p. 33).

As políticas públicas de saúde e nutrição, especialmente aquelas voltadas para mulheres, crianças, escolares, idosos e populações vulneráveis, são fundamentais para a melhora dos indicadores de saúde e sociais. Melhorar a nutrição da população é essencial para a redução da pobreza e para a melhora dos níveis educacionais. Além disso, é uma maneira inequívoca de quebrar o círculo perverso de transmissão intergeracional da pobreza e da desnutrição (BRASIL, 2013a, p. 37).

\footnotetext{
3 “A Política Nacional de Segurança Alimentar e Nutricional (PNSAN) está prevista na Lei Orgânica de Segurança Alimentar e Nutricional (LOSAN) e foi instituída pelo Decreto 7.272, de 2010. Ela tem como objetivo geral 'promover a segurança alimentar e nutricional, (...) bem como assegurar o direito humano à alimentação adequada em todo território nacional' (BRASIL, 2013a, p. 36).
} 
A partir da compreensão de que a saúde tem como determinante e condicionante a alimentação "a garantia de alimentos seguros e nutritivos para as crianças e, além desses, o direito das mulheres e da família de dispor de informações adequadas e condições que favoreçam suas decisões quanto à alimentação de seus filhos na primeira infância são poderosos instrumentos de promoção da saúde e da qualidade de vida" (BRASIL, 2017, p. 23). E mais além, "os direitos fundamentais de mulheres e crianças, particularmente os relacionados à alimentação segura e nutrição adequada, universalmente reconhecidos são um dos aspectos essenciais para que esses grupos populacionais possam gozar de elevados padrões de saúde e de vida" (BRASIL, 2017, p. 23).

Contudo, conforme o discurso na $5^{\mathrm{a}}$ Conferência Nacional de Segurança Alimentar e Nutricional em 2015, identifica-se que apesar de toda complexidade relacionada à segurança alimentar e nutricional, que considera questões ligadas à cultura, sustentabilidade, qualidade, quantidade, soberania, dentre outras, raramente surge a amamentação dentro das discussões ligadas ao direito à alimentação adequada. Quando falamos em aleitamento materno nos referimos ao primeiro alimento que qualquer ser humano deveria ter acesso e, mais além, ao longo dos primeiros seis meses de vida o leite materno representa o único alimento necessário ao bebê, que promove todos os nutrientes necessários para suprir as demandas decorrentes do seu intenso desenvolvimento e oferece proteção imunológica para um organismo que nasce com poucos mecanismos de defesa já estabelecidos.

Por isso, compreende-se que a prática da amamentação contribui para a promoção e defesa do Direito Humano à Alimentação Adequada e o Direito à Saúde, ao ampliar o acesso ao primeiro alimento do ser humano: o leite materno, que é um alimento seguro e nutricional; e ao promover e proteger a saúde, através dos diversos benefícios proporcionados pela prática da amamentação tanto para as crianças como para as mães.

Portanto, compreendendo que a saúde tem como determinante e condicionante a alimentação, "a garantia de alimentos seguros e nutritivos para as crianças e, além desses, o direito das mulheres e da família de dispor de informações adequadas e condições que favoreçam suas decisões quanto à alimentação de seus filhos na primeira infância são poderosos instrumentos de promoção da saúde e da qualidade de vida" (BRASIL, 2017, p. 23) e sendo à alimentação segura e nutrição adequada direitos fundamentais universalmente reconhecidos, temos um dos aspectos essenciais para que as crianças possam gozar de elevados padrões de saúde e de vida.

\section{Considerações Finais}


Entendendo que a amamentação está imbricada de determinantes biológicos, sociais, econômicos, políticos, culturais e ideológicos materializados através de diferentes discursos que ao longo dos anos transformou a amamentação em uma prática regulável pela sociedade, este trabalho possibilitou a compreensão do ato de amamentar como promotor do Direito Humano à Alimentação Adequada e o Direito à Saúde, entendo que este também é um Direito da mãe: em praticar ou não tal ato, livre de culpa, opressões e acusações diante das dificuldades ou insucessos.

Da mesma forma, possibilitou o entendimento e a defesa de que o Direito Humano à Alimentação Adequada e o Direito à Saúde da criança perpassa necessariamente pelo direito da mãe de praticar o aleitamento materno exclusivo até os seis meses e continuado até os dois anos ou mais, e/ou de ser informada sobre as melhores alternativas, no caso de ela não poder ou decidir não amamentar, livre de toda influência ocasionada pelo discurso de outras pessoas, dos profissionais de saúde e/ou das indústrias de leites industrializados, entre outros.

O trabalho propiciou o entendimento de que as vantagens que a amamentação oferece permite afirmar que não há outra forma de alimentar os bebês que seja equivalente ao aleitamento materno, "no entanto, a amamentação não é uma torneira que pode ser aberta ou fechada. Ela depende da autoconfiança da mãe, da proximidade entre ela e seu filho, da facilidade para amamentar a qualquer momento e da aprovação da comunidade" (BRASIL, 2009a, p. 16).

$\mathrm{O}$ ato de amamentar é muito mais do que essencialmente um ato biológico e natural de alimentar fisicamente o bebê. É natural, na medida em que ocorre o processo biológico que se inicia desde e durante o trabalho de parte para a produção e descida do leite materno, porém também é uma prática que precisa ser apreendida, compreendendo que o ato de amamentar é um comportamento social, permeado por dificuldades, dúvidas, medos, crenças, entre outros, em que as mães se sentem culpabilizadas e impotentes ao não conseguirem realizar tal prática.

Amamentar é um ato de autoconhecimento, de aprendizagem entre as mães e os bebês e neste momento todo apoio, promoção e proteção é essencial, seja pela família, pela sociedade ou pelo Estado, por isso a importância de ações, estratégias, leis e portarias que contribuam para aumentar a prevalência e a duração do aleitamento materno. Ações, estratégias, leis e portarias que atualmente estão sendo as bases para a discussão e pactuação de uma Política Nacional de Promoção, Proteção e Apoio ao Aleitamento Materno no Brasil, compreendendo que por meio dessa Política Social direitos sociais se concretizam, como o Direito Humano à Alimentação Adequada e a Saúde, atuando no enfrentamento da cultura do desmame precoce e atendendo as necessidades humanas na perspectiva da cidadania ampliada. 


\section{Referências}

ALMEIDA, João Aprigio Guerra de. Amamentação: um híbrido de natureza e cultura. Rio de Janeiro: Ed. Fiocruz; 1999.

BRASIL. Constituição da República Federativa do Brasil de 1988. Brasília, 1988. Disponível em: <http://www.planalto.gov.br/ccivil_03/constituicao/constituicaocompilado.htm>. Acesso em: 21 mar. 2019.

BRASIL. Lei Orgânica da Saúde. Lei nº 8.080, de 19 de setembro de 1990. Brasília, 1990. Disponível em: <http://www.planalto.gov.br/ccivil_03/Leis/L8080.htm>. Acesso em: 21 mar. 2019.

BRASIL. Lei no 11.265, de 03 de janeiro de 2006. Regulamenta a comercialização de alimentos para lactentes e crianças de primeira infância e também a de produtos de puericultura correlatos. Brasília, 2006a. Disponível em: < http://www.planalto.gov.br/ccivil_03/_Ato20042006/2006/Lei/L11265.htm>. Acesso em: 28 abr. 2019.

BRASIL. Lei $\mathbf{n}^{\mathbf{0}}$ 11. 346, de 15 de setembro de 2006. Cria o Sistema Nacional de Segurança Alimentar e Nutricional - SISAN. Brasília, 2006b. Disponível em: < http://www.planalto.gov.br/ccivil_03/_ato2004-2006/2006/lei/111346.htm>. Acesso em: 22 mar. 2019.

BRASIL. Ministério do Desenvolvimento Social e Combate à Fome. O direito humano à alimentação adequada e o sistema nacional de segurança alimentar e nutricional. Brasília: ABRANDH, 2013a.

BRASIL. Ministério da Saúde. A legislação e o marketing de produtos que interferem na amamentação: um guia para o profissional de saúde. Brasília: Editora do Ministério da Saúde, 2009a.

BRASIL. Ministério da Saúde. Bases para a discussão da Política Nacional de Promoção, Proteção e Apoio ao Aleitamento Materno. Brasília: Editora do Ministério da Saúde, 2017.

BRASIL. Ministério da Saúde. Política Nacional de Alimentação e Nutrição. Brasília: Editora do Ministério da Saúde, 2013b.

BRASIL. Ministério da Saúde. Saúde da criança: nutrição infantil: aleitamento materno e alimentação complementar. Brasília: Editora do Ministério da Saúde, 2009b.

BRAVO, Maria Inês Souza. Serviço Social e Reforma Sanitária: Lutas Sociais e Práticas Profissionais. São Paulo: Cortez, 1996.

CLIMEP. Clínica de Medicina Preventiva do Pará. Amamentação reduz o risco de obesidade na vida adulta. 2018. Disponível em: < http://www.climep.com.br/amamentacao-reduz-o-riscode-obesidade-na-vida-adulta/>. Acesso em: 21 abr. 2019.

ENY, Érica Macedo; NASCIMENTO, Maria de Jesus Pereira de. Causas e consequência do desmame precoce: uma abordagem histórico-cultural. Universidade de Santo Amaro, 2001, p. 52-56. Disponível em: <http://www.unisa.br/graduacao/biologicas/enfer/revista/arquivos/200111.pdf $>$. Acesso em: 22 mar. 2019.

ESCOBAR, Ana. Leite Materno: veja as mais recentes descobertas. 2018. Disponível em: $<$ https://g1.globo.com/bemestar/blog/ana-escobar/post/2018/09/17/leite-materno-veja-as-maisrecentes-descobertas.ghtml?utm_source=facebook\&utm_medium=share-barsmart\&utm_campaign=share-bar $>$. Acesso em: 21 set. 2018.

FORTI, Valéria; BRITES, Cristina Maria. Direitos Humanos e Serviço Social: Polêmicas, Debates e Embates. Rio de Janeiro: Lumen Juris, 2013.

GIUGLIANI, Elsa Regina Justo. Aleitamento Materno: aspectos gerais. In: DUNCAN, Bruce; SCHMIDT, Maria Inês; GIUGLIANI, E. R. J. Medicina ambulatorial: condutas de atenção primária baseados em evidências. 3. ed. Porto Alegre: Artmed, 2004, p. 219-231.

GUERRA, Sidney. Direitos Humanos na Ordem Jurídica Internacional e Reflexos na Ordem Constitucional Brasileira. Rio de Janeiro: Ed. Lumen Juris, 2008. 
HOJE EM DIA. Pesquisa da UFMG mostra que fígado de bebê pode ter problemas com interrupção na amamentação. 2018. Disponível em: < https://www.hojeemdia.com.br/horizontes/cidades/pesquisa-da-ufmg-mostra-quef\%C3\%ADgado-de-beb\%C3\%AA-pode-ter-problemas-com-interrup\%C3\%A7\%C3\%A3o-naamamenta\%C3\%A7\%C3\%A3o-1.654973>. Acesso em 29 abr. 2019.

PEREIRA, Bruna Tereza. Aleitamento Materno Exclusivo: um estudo sobre as causas do desmame precoce na Associação Beneficente de Saúde do Oeste do Paraná - Hoesp. Trabalho de Conclusão de Curso (Bacharelado em Serviço Social). Centro de Ciências Sociais Aplicadas. Universidade Estadual do Oeste do Paraná - Campus Toledo-PR, 2016.

SIMONS, A. D. Alimentos complementares ao desmame: quais, como e quando introduzi-los. In: REGO, José Dias. Aleitamento Materno. São Paulo: Atheneu, 2001. p. 299-312.

Recebido em 04/05/2019 - Aprovado em 15/07 de 2019. 